\title{
Revisiting Friedrich Engels's Dialectics of Nature in an Age of Digital Idealism
}

\author{
Christopher Leslie
}

South China University of Technology, Guangzhou, and Zhejiang Hexin Group, Yunhe County, People's Republic of China, chrisleslienyc@hotmail.com

\begin{abstract}
The idealism that Fredrich Engels seeks to defeat in Dialectics of Nature today pervades online discourse and pedagogies of science, technology, engineering, and mathematics (STEM). The deterministic view that STEM is dedicated to unleashing the inherent power in objects for the service of privileged societies fails to understand the basic principles that Engels proposed. Engels exposes his contemporaries' flawed understanding of science and technology and provides interdisciplinary examples that exemplify a different way of thinking. Outside of China, Engels's ideas have been used suggest that social considerations cannot be a part of science because they limit the free exchange of ideas. Within China, particularly after the establishment of the People's Republic in 1949, these ideas have been the basis of new thinking about the relationships among developers, the government, and the people. Moreover, readers of Dialectics of Nature who are familiar with the basic tenets of Science and Technology Studies (STS), such as social constructivism and actor-network theory, will not be so impressed with the idea that social theory has no place in understanding science and engineering. This analysis suggests avenues of cooperation for international science studies. In addition, it provides a starting point for pedagogies to promote the development for science and technology that reduces inequality and supports the notion that the liberal arts have an important place in the study of science and engineering, an insight known as STEAM.
\end{abstract}

Keywords: Dialectics of Nature, Friedrich Engels, Science and Technology Studies, social constructivism, STEAM, sustainable development

\section{Introduction}

Friedrich Engels's unfinished Dialectics of Nature, which was written mainly from 1872 to 1882 , offers an interdisciplinary approach to communicating about science. The way we talk about scientific discovery, to Engels, seems as if power is being released in one direction: the force of evolution, the application of electricity. We assume the natural world is unchanging. When teaching engineering students about the history of technology in Brooklyn, N.Y., one of my favourite conversations was with students who did not believe that technology had a history. They had been carefully prepared by their families and secondary schools for success in science, technology, engineering, and mathematics (STEM), so their antipathy toward taking a liberal arts or social science look at engineering seems indicative of a larger ideological challenge.

One semester, I was teaching two courses that incorporate the liberal arts, such as literary study or history, with the study of STEM, an idea that has now been called STEAM by Yakman (2008). A student who attended the first meeting of my history and philosophy of the Internet class surprised me by adding my science and literature class the second week. I felt flattered, thinking that I had impressed him so much that he decided to take two humanities electives with me. The student quickly disabused me, informing me that engineers do the best they can with the tools they have available, so there is no such thing as interaction between the social world and innovation. 
Had the student chosen to spend a few more weeks in the class, I would have been happy to introduce him to the robust scholarship about social constructivism in Science and Technology Studies (STS) that shows how engineers are always imagining users when they are working, and that the social world is always shaping which technological choices seem to be right through law, ideology, economics, history, and even the physical environment. To me, it seems obvious that people who are striving to be innovators would benefit from understanding how judgements are made about new developments, either fitting them in with current thinking or by finding allies when they hope to be disruptive. Indeed, the modern field of STS owes much to a group of Scandinavian scholars who, in the 1980s, hoped to understand how larger economic, historical, and political circumstances made it easier for an oligarchy of companies from an elite group of nations seemed so often succeed. These early practitioners had the goal of understanding why smaller companies cannot set industry standards that promote their own interests.

We live at a time with pervasive harmful ideologies about science and technology. In the news and in government rhetoric, audiences witness a deterministic attitude that technology is independent of society, perhaps developing so fast that culture and the law cannot keep up with it. Many students, faculty, and professionals in STEM believe that it is their duty to provide the most efficient and cost-effective innovation to market, whereas considering social issues (not only supporting equity and eliminating poverty, but also eliminating unearned privilege in STEM careers) are tasks somehow exterior to scientific and technical research. One group of students and colleagues always seems to deride any attempt to connect words like "philosophy" with science or engineering, and there is always a gendered undertone to the criticism: historical or philosophical analysis is about feelings and opinions, which have nothing to do with science.

To be fair, many STEM students take an interest in these topics, so much so that we founded an interdisciplinary undergraduate major in STS in 2005. For some - particularly members of demographic groups that had been traditionally excluded from engineering (based on gender identity, ethnicity, or national origin) - the opportunity to study why science and technology seem to reinforce existing social assumptions and fail to benefit all strata of society equally. In this context, Engels's ideas are a strong reminder that the disconnect between science, technology, and society was resisted from the first days of the industrial revolution. His notes and ruminations in the unfinished text offer a starting point for further work on equitable and sustainable development that can come from sound science and technology policy.

\section{Dialectics and the Second Industrial Revolution}

One might rightly wonder about the motivation for Engels preparing a book about the dialectics of nature (the title in German is Dialektik der Natur; the noun Dialektik without an article indicating a plural). The examples in his book are more often about what today we would consider science and the secondary literature is interested in Engels's supposed scientific method. Would not Dialektik der Wissenschaft (Dialectics of Science) or something similar be more appropriate? In fact, several of Engels's word have something to say about the history of science and how to best understand his ideas.

Using the word scientist to describe a person is relatively new, the word originating in a book review by William Whewell in the mid-nineteenth century, contemporary with Marx and Engels. The word science is older, but it referred to the end process of studying: what someone has learned. What Engels calls "Die moderne Naturforschung" in the introduction is translated in MECW as "modern natural science," but Engels's phrase is more of a vexed locution than it might appear. Understanding his choice of 
"Naturforschung" (closer in meaning to investigation of nature) ${ }^{1}$ over something like "Wissenschaftsforschung" (science studies, or science of science) might be difficult to fathom, except that there are several contextual clues.

First, the conflict between natural philosophy and natural history illuminates the focus of this work. STS scholars point to the debates between Thomas Hobbes and Robert Boyle in the late seventeenth century. Although their disagreement is largely remembered for Hobbes's incorrect statement that there could be no vacuum, a foundational text in STS states that the controversy was more about the proper method to investigate the natural world (Shapin and Schaffer 2011). Hobbes, uneasy about dissent in the wake of the English civil war, expected that science should proceed deductively from known principles and explain phenomena so clearly that no one could disagree. Like a geometric proof, someone could misunderstand, but no one could disagree. The name for this endeavour was natural philosophy. Boyle, for his part, preferred to work from what he saw, the small observations building up to a conclusion inductively. Boyle demanded that science be based on what is "sensible," while Hobbes said that the human senses are easily fooled; Hobbes's distaste for Boyle's work - the impression that Boyle was simply recording the incidents before him - led to what he thought of as an epithet; nonetheless, natural history eventually came to be used by the followers of Boyle. This is seen in the institutions that took the name, such as the 1793 Muséum national d'histoire naturelle in France.

William Whewell, one of Charles Darwin's professors at Cambridge, helped formalise the inductive method of the natural historians. Darwin's work is a triumph of the inductive method, building from minute observations he started to collect while on board the Beagle and eventually from empirical investigation to support the supposition that species evolved from one into the other, an idea first credibly proposed by a researcher at Paris's natural history museum, Jean Baptiste Lamarck. In spite of Darwin's ultimate conclusion - that chance and history formed species, with unexpected benefits from random differences giving a group a greater ability to reproduce - his teacher and his contemporaries were not convinced that nature was changing in the way Darwin proposed; they preferred to think that evolution was progress toward perfection. Whewell (1840) starts off his text with the first principle: "Man is the Interpreter of Nature, Science the right interpretation" (xvii). Whewell's interest in the inductive method was to gain access to the one, true nature. For instance, Whewell's aphorism number 56 concerning science reads: "In contemplating the series of Causes which are themselves the effects of other causes, we are necessarily led to assume a Supreme Cause in the Order of Causation, as we assume a First Cause in Order of Succession" (xlvii). Regardless of the conflict between natural philosophers and natural historians, they seem unified in their presumption in a singular, unified world.

This contradiction is noted by Engels when he provides a short history of science. The English-speaking world might mark the age of science with the Boyle-Hobbes debate, but for Engels, modern science was continuation of the Protestant Reformation. In 1517, when Martin Luther published his objections to the Church, Engels sees the beginning of "Naturforschung", the time when free inquiry supplanted theology. Notwithstanding these conflicts, Engels saw the process unfinished. In particular, the growing investigation was limited by an unexpected continuity: "Science was still deeply enmeshed in theology" (Engels 1925, 322). Engels suggests the revolution was

${ }^{1}$ An important eighteenth-century German scientific journal was Der Naturforscher; this title might best be translated as "The Naturalist". 
unfinished because savants were still seeking the one, unchanging universe, as if it had been created by a deity.

This difference of understanding can be seen in later considerations of the dialectic as described by Emery (1935). With dialectics, objects are always in the midst of forces; "no matter exists without motion" (18). An idealism that was identified by Newton and fostered during the Enlightenment suggests that matter and movement are two separate things; objects are stable unless they are acted on. Every action has a cause and the same action always obtains the same result; there is no place for chance (31). Extrapolating this view of the natural world, it can be wrongly assumed that human beings are, in their natural state, independent of each other. A religious reverence for absolute space and absolute time hinders an understanding of the interrelationships in nature. Engels (1925) writes that the underlying belief was that of "the absolute immutability of nature" (321). He continues:

In contrast to the history of mankind, which develops in time, there was ascribed to the history of nature only an unfolding in space. All change, all development in nature, was denied. Natural science, so revolutionary at the outset, suddenly found itself confronted by an out-and-out conservative nature in which even today everything was as it had been at the beginning and in which - to the end of the world or for all eternity - everything would remain as it had been since the beginning (322).

A triumph of this world in flux was when Darwin in his 1859 Origin of Species proposed that evolution was based on the competition for scarce resources, some species finding an advantage due to unexpected morphology. At a time when techniques for production had made it possible "so that a child now produces more than a hundred adults previously did," Engels (1925, 331) writes that this understanding of nature was no benefit because of the misery of so many human beings. Making a connection between material history and the history of science, Engels $(1925,331)$ writes that Darwin wrote a "bitter satire" when he showed that the so-called free market celebrated by economists "as the highest historical achievement" but is really just the normal conditions of the animal kingdom. He continues:

Only conscious organisation of social production, in which production and distribution are carried on in a planned way, can lift mankind above the rest of the animal world as regards the social aspect, in the same way that production in general has done this for men in their aspect as species. Historical evolution makes such an organisation daily more indispensable [unumgänglicher, which could also be 'inevitable'], but also with every day more possible. From it will date a new epoch of history, in which mankind itself, and with mankind all branches of its activity, and especially natural science [Naturwissenschaft ${ }^{2}$ ], will experience an advance that will put everything preceding it in the deepest shade (Engels 1925, 331).

Clearly, Engels takes inspiration from the idea that the incomplete realisation of the Reformation on science, which was now showing that the world was changeable, could now serve as a rationale for political change. Key to this different mode of thought is the reciprocal actions of humans and their environment. Keeping in tune with the idea

${ }^{2}$ The translators use "natural science" for both Naturwissenschaft and Naturforschung. 
that humans create their own society, Engels points out that the separation of the natural world and the human history is a myth:

Natural science [Naturwissenschaft], like philosophy, has hitherto entirely neglected the influence of men's activity on their thought; both know only nature on the one hand and thought on the other. But it is precisely the alteration of nature by men, not solely nature as such, which is the most essential and immediate basis of human thought, and it is in the measure that man has learned to change nature that his intelligence has increased. The naturalistic conception of history, $[\ldots]$ is therefore one-sided and forgets that man also reacts on nature, changing it and creating new conditions of existence for himself. There is devilishly little left of 'nature' as it was in Germany at the time when the Germanic peoples immigrated into it. The earth's surface, climate, vegetation, fauna, and the human beings themselves have infinitely changed, and all this owing to human activity (Engels 1925, 511; emphasis in original).

Engels rejects a teleological idea of evolution, one that was supported by natural philosophy, but does not often directly address capitalism in this text. Instead, he attacks the ideological foundations of capitalism that derive from the Enlightenment. After all, Newton's laws of motion and Adam Smith's analysis of capitalism are contemporaries. They both assume that the universe is unchanging but filled with the potential to unleash force in order to accomplish work. He seeks to expose this fallacy by showing that nature consists at its basic level as entities that are always divisible and that are always operating on each other. At a higher level, he seeks to embrace the continuing scientific revolution, rejecting a one-sided science that is only designed to exploit nature and forging the notion that human beings have different options. In this way, he seeks to build on the appeals to science and human rights espoused, but not necessarily achieved, by the natural historians.

\section{Dialectics During the Communication Revolution}

One should not underestimate the way in which interdisciplinary scientific metaphors were bandied about while Engels was writing. Spencer and other proponents lent authority to their public statements about racial hierarchy through analogy to the new science of thermodynamics. Conservation of energy, to Spencer, was the reason why eventually humanity would inevitably evolve into a homogenous, superior species. He presumed that at the lower levels of the evolutionary tree, a proliferation of types was possible because they were not too complicated and required less life energy. Moving up the ladder of complexity required more energy, meaning that nature could no longer support a proliferation of types. Thus, there are more types of mould then there are mammals. The higher the form of life, the less energy there was for diversity, and the inevitable result would be one form of humanities. The evidence for this, according to the social Darwinists, was the coming extinction of aboriginal people and the spread of the so-called "white race".

Engels did not directly address the connection between the second industrial revolution and what historians now call the scramble for Africa, the forty-year period when almost ninety percent of the continent was brought under colonial control (Chamberlain $2013,3)$. It is possible to see how the theory that technology is dependent on the exploitation of nature is implicated in the process of colonization. The raw material needed for the communication revolution in the latter part of the nineteenth century material such as tin, lead, rubber, gemstones, and precious metals - was most easily 
obtained through colonial power. The pseudoscience of racial evolution, suggesting that one superior race would the inevitable and best outcome of humanity and the rest of humanity was doomed to inevitable destruction, was a consequence of forcing Darwin's thinking into the teleological prejudices of the time. The objective and democratic ideals of Enlightenment science were tainted by an eschatological belief akin to religion, The uneven nature of technical development during and after the industrial revolution, as de Sousa Santos (2018) has pointed out, calls into question the dream of "science for all" that began in the Enlightenment. The self-congratulatory notion of natural philosophers in the eighteenth century that anyone could participate in science was coincident with the dream of universal human rights that would benefit all of humanity. However, this idealist dream did not imagine the consequences of combining science with capitalism. He writes:

capitalism would be inherently unable to relinquish the concept of the subhuman as an integral part of humanity, that is to say, the idea that there are some social groups whose existence cannot be ruled by the tension between regulation and emancipation (de Sousa Santos 2018, 276)

In Dialectics of Nature, Engels seeks to improve the ideals of the Reformation and promote the best aspects of the scientific revolution by means of a philosophy that would not require the subjugation of humans, but is faced with a communication problem similar to Darwin's. In spite of Darwin's assertion that chance and not superiority drove species to succeed, the popular understanding was that superior abilities derived from evolutionary forces. Presumptions about the calm organisation of humanity infused the popular understanding of the natural world in the nineteenth century. Both bees and birds fly, but no one would expect them to mate - the supposedly unique and unchanging characteristics of those species used hyperbolically to support laws against miscegenation and supporting race-based slavery.

No matter what Darwin tried to communicate, his ideas were forced into the existing paradigm of normal science to form social Darwinism, which was invested not just in a hierarchy of races but also the idea that the economic and legal systems intrinsic to the industrial revolution should dominate the world's systems. It was, after all, not Darwin but Herbert Spencer who coined the phrase "survival of the fittest". Human superiority due to using tools is the emblem of this ideology. The social Darwinist interpretation of evolution would suggest that evolution gave humanity a hand, which then allowed humans to exploit nature by the use of tools. The survival benefit from tools for social Darwinism thus a deterministic event, and one can suppose that the humans who use the best tools are the ones who are the fittest to walk the earth. Engels describes this interpretation as one that highlights the exploitation of a unidirectional force.

In the same way that Darwin's work undermines the way in which the findings of natural history were used to support public arguments to support slavery, ${ }^{3}$ Engels

${ }^{3}$ The subtext of Origin of Species is Darwin's belief that there was only one human species, a supposition that would undermine claims that some races were biologically distinct and better off being enslaved (Desmond and Moore 2011). Although he does not directly attack the institution of slavery, his work is full of examples that undermine the justification for slavery: how biological organisms are not members of pure species, that diversity provides species with a robust defence against adversity, and that chance less than superiority accounts for why some species are more successful in an environment. It is worth mentioning that Darwin's companion to Origin of Species, Descent of Man, was first published in 1871, which is 
shows how the communication of science was still in service of a priest-like power. For Engels, the scientific revolution should have stopped the priestly practice of an elite caste standing between humanity and a great eminent power, and yet paradoxically the natural scientists seemed to have taken the place of the priests. Despite the revolution, they still stood as an elite between power and the people.

Engels's description of the evolutionary power of the human hand illustrates how he expects the public to see dialectics in something as fundamental as the formation of humanity. In his discussion of the hand, Engels shows evolution to be a balance of contradictory forces and, at the same time, that dialectics were in fact an intrinsic principle of the universe. There was no release of force that gave humanity a hand and then created a superior species, Engels points out. Instead, there was a recursive process. The early form of the hand allowed mammals to manipulate their environment and later primitive tools. Being able to walk upright made the use of tools easier, the accident that increased cranial capacity made it possible to use tools smarter. Using better tools with better intelligence created success for the species, which then allowed for humans to take advantage of further biological modifications. The tool and humanity were thus bound in a reciprocal process of evolution. He then makes the connection to the industrial revolution:

Man alone has succeeded in impressing his stamp on nature, not only by shifting the plant and animal world from one place to another, but also by so altering the aspect and climate of his dwelling place, and even the plants and animals themselves, that the consequences of his activity can disappear only with the general extinction of the terrestrial globe. And he has accomplished this primarily and essentially by means of the hand. Even the steam engine, so far his most powerful tool for the transformation of nature, depends, because it is a tool, in the last resort on the hand. But step by step with the development of the hand went that of the brain; first of all consciousness of the conditions for separate practically useful actions, and later, among the more favoured peoples and arising from the preceding, insight into the natural laws governing them. And with the rapidly growing knowledge of the laws of nature the means for reacting on nature also grew; the hand alone would never have achieved the steam engine if the brain of man had not attained a correlative development with it, and parallel to it, and partly owing to it" (Engels 1925, 330).

Certainly, as in his example of the human hand, one cannot simplistically say that humans are superior because they use tools; humanity and human tools evolved together. Engels's more technical descriptions - like his discussion of the reciprocal action of electrons that opposes the popular notion of unleashing electric force - show how culture and ideology clouds insight and hinders innovation.

In addition to well-developed and thoughtful analyses like these are comments in the text about how the failure to consider the dialectical nature of technical development leads to unexpected impacts in the social world. For instance, Engels wonders whether the Arabic scientists who first discovered how to distil alcohol could have ever imagined how spirits would be one of the tools used to subjugate indigenous populations. An individual who believes in the objective and disinterested nature of scientific progress would say it was not any of the original scientists' fault that their discovery

during the time Engels was writing. Desmond and Moore propose that the implications of natural selection on humanity rejected so much of Darwin's contemporaries that he delayed extending his finding to humans for twelve years. 
was used this way. This is not the only and best way to consider scientific discovery, however. One can make the argument that it is precisely the responsibility for innovators to account for what can go wrong and to build up safeguards against misuse, always considering the impact on the social fabric.

Another example Engels mentions without much development is the steam engine, which certainly played a leading role in the Manifesto. On the one hand, Engels praises the development of the steam engine because it was one of the first truly international inventions. The fact that scientists and practitioners in so many different countries contributed to the abstract theory and practical development of the steam engine indicates the degree to which the world had become a global community at the turn of the eighteenth century. The way the steam engine was put into use for manufacturing, though, had a negative impact on the masses of workers. No one developing the steam engine seems to have thought about the misery and loss of autonomy that production methods would have brought about.

Although the use of steam power caused a crisis for the working class, what goes unstated by Engels is that the international nature of this crisis provided the international opportunity for a response to change the way that the technology was being used. Throughout this interplay of competing forces, Engels is consistent in his assertion that these various developments are not inevitable, but a peculiar result based on specific circumstances. He notes that animals have a history, in the sense they have path through evolution, but "this history, however, is made for them" and it "occurs without their knowledge or desire" (Engels 1925, 330). The further humanity moves away from animals, "the more they make their own history consciously" (330). No longer at the mercy of "unforeseen effects and uncontrolled forces" (330-331), human history is made in correspondence with "the aim laid down in advance" (331). In this way, Engels repudiates the sense of inevitability of so-called human progress, showing how materialist notions of history are consistent with what we assume to be natural.

\section{Reception in the Communist Sphere}

Dialectics of Nature was translated into Russian and published in the Soviet Union in 1925, which developed a "rigid application of Engels's three laws" (Royle 2014, 106). In 1929, scientific leaders gathered in Moscow to debate the virtues of dialectic materialists and the opposing school of idealists. Those supporting the dialectic position that scientific processes are "creative and synthetic" - ultimately "had a full victory", but this did not end the debate (Emery 1935, 11-12). By 1932, a prevailing notion that natural science is part of the ideological superstructure, akin to religion, and influences the means of production by fostering relationships was developed (Joravsky 1955, 5). Science instead should be seen as conditioned by "historical circumstances" and derives from a "world treasure-house" that is stocked by contributions from national communities, rather than individuals operating in a "cosmopolitan community of scientists".

After World War II, a sense of Soviet pride in national achievement and, with the rise of the cold war, antagonism toward the idea that so-called western civilization excludes Russian culture, "either implicitly or explicitly" (Joravsky 1955, 8-9). It is here that Dialectics of Nature is extrapolated to become a more direct critique of capitalism. As the cold war was about to get underway, though, Soviet communists took on a new target: Albert Einstein's theory of relativity. In June 1947, Andrei A. Zhdanov wrote about his concern that Einstein's theory was leading individuals to believe in a closed, finite universe (Hu 2005, 142). Although it is tempting to classify discounting of Einstein's work simply as wrong, we should take a page from Shapin and Schaffer (2011) and consider the nature of the controversy from an insider's point of view. For Russia, 
Einstein's work resulted in a network of nations that would restrict access to technology to reinforce the world system announced by U.S. Secretary of State George C Marshall in the same month that Zhdanov made his first statement. The next month, Soviet Foreign Minister V. M. Molotov would walk out of a meeting about the Marshall plan and initiate its own community of nations, the council for Mutual Economic Assistance.

China's interest in communism coincided with the reception of Dialectics of Nature. Starting in 1909, the U.S. used surpluses from the indemnity of the Boxer rebellion to fund science and engineering education for Chinese citizens. Shortly after the overthrow of the Qing Dynasty in 1912, people who might be called Boxer fellows formed a Chinese science society in 1914 and began publishing a journal, Kexue (科学 or science), the next year (Wang 2002, 294; 299). A famous formulation by Chen Duxiu arose in the early days of the Republic of China: Mr Science and Mr Democracy were the antidotes to the legacy of feudalism. In response to the failure to return the German holdings in Shandong province to China as part of the World War I peace process, intellectuals including Chen began seeking a political system that would help fight imperialism in what became known as the May Fourth movement in 1919. He would then go on to be one of the founders of the Communist Party of China (CPC) in 1921 and its general secretary until 1927. Although the appeal of gentlemanly Mr Science and Mr Democracy is understandable, it recalls the Internationale sentiment that China's communists lacked sufficient connection to the working class. Even so, Engels's Dialectics of Nature took on a special role at a time when Chinese intellectuals were trying to help their country recover after being left out of the industrial revolution thanks to the Opium Wars. Gao $(2016,270)$ says China sought to apply Engels's thought as a guide to transform the "agricultural nation to an industrialized power". Engels's chapter on "Labour in the Transition from Ape to Man" was translated into Chinese in 1928, and the whole of Dialectics of Nature was translated in 1932.

In 1956, the People's Republic of China adopted a long-term development plan that demanded the use of dialectics of nature. Mao Zedong himself addressed the topic in several essays (Guo 2014). As overseas Chinese scholars returned to the new PRC, they wished to provide guidance on how the development of science and technology might be ideologically different than they had known outside of China (Gao 2016). In other words, insights from Engels were used as a basis for science policy in the People's Republic. Engels's work took on new significance when it came to the attention of Mao Zedong that the Japanese, who could not match the Europe and the United States in equipment for nuclear research, nevertheless "had been able to propose a number of important hypotheses in elementary particle physics because they had read Engels's Dialectics of Nature" (Cheng 2013, 203). The idea that an atom's neutrons and protons could be divided into smaller parts reaffirmed the correctness of Engels's ideas and cemented for Mao the efficacy using dialectics in science. This led to a number of initiatives, perhaps the most famous being an attempt to criticise Einstein's ideas as bourgeois. This critique softened somewhat, and in 1973 the Journal of Dialectics of Nature was founded as a means to discuss Maoist theories of science (Cheng 2013, 213). This journal was disbanded in 1976.

Following Russia's lead, the CPC also initiated a campaign against Einstein. In the early 1950s, translations of Soviet criticism of Einstein found their way into newspapers. At first, Chinese scientists continued to "venerate" Einstein and point out the way his writing fit in with dialectical materialism (Hu 2005, 144). However, in the context of the cultural revolution, indigenous criticisms of Einstein arose. Writers noted that Einstein had served imperialism by helping create the atom bomb, as pointed out $\mathrm{Hu}$ (2005, 149-150), "which, in the hands of American imperialists, became a tool to blackmail and threaten socialist countries and other peace-loving countries in the world". Criticisms also were made of the way his theory negatively impacted the public's worldview. Hu $(2005,150)$ complains that it was widely known that Einstein did not 
directly participate in the Manhattan Project, but again the lessons from the BoyleHobbes debate should be followed here: while individuals may criticise the CPC for condemning relativity on ideological grounds, the concern was truly an effort to criticise bourgeois science, of which Einstein was the most famous emblem. In criticising Einstein in 1968, China hoped to inspire a proletarian science. By 1971, Premiere Zhou Enlai sought to soften the attack (Cheng 2013, 209). While some western observers seem gleeful in the way they discredit ideological influence on the development of science, it is not so radical to request that social considerations of science be taken into account.

After the cultural revolution, it became clear that finding people to develop plans for China's could be "overly ambitious" and government needed experts who could "develop a more realistic picture [...] and assess what it was possible to achieve in the near future" (Elzinga 1981, 19). In the period of market reform and opening up initiated by Deng Xiaoping, China moved away from what came to be seen as the rigid strictures of Soviet communism to form what he called "socialism with Chinese characteristics". Interestingly, the theories espoused by Engels took on an enhanced role after 1978, even if the three dialectical laws (negation and interpenetration of opposites, transition from quantity to new qualities, negation of the negation/Aufhebung [sublation]) were deemphasized.

The Chinese Society for the Dialectics of Nature was established in 1981, and a journal Research on Dialectics of Nature began publication in 1985. Although the PRC would embrace privatisation and market development, it still wished to do so in a responsible manner. The early days of the journal show enthusiasm for educational reform; STEM students were happy to see that their technical subjects were relevant to political philosophy of their country (Hou 1985). Scholars and journalists were invited to share their ideas in the first issue on how dialectics could guide the development of science and technology in China. In the second issue, one article described the development of Science and Technology Studies as a discipline outside of China (Jiang 1985). Another article analysed the US's big science system of funding scientific research (Yang and Zeng 1985). These articles represent both a speculative application of Engels's ideas as well as how their application might differ from capitalist contexts.

The contributors to this journal demonstrate the challenge faced by China after the cultural revolution, especially those represented in an anthology of English translations (Fan and Cohen 1996). Yu (1996) proposes that the 1915 formulations of Mr Democracy and Mr Science have been transformed by socialism into Comrade Democracy and Comrade Science (2). Similarly, Xu (1996) admits that science is the backbone of modern societies; all can see how science brings democratic ideals along with it. The difficulty is expunging from science bourgeois ideals that exploit science for "building up capitalist fortunes" (6). Science and democracy are both "precious spiritual legacies of the totality of human history" and the basis of Marxism (10). Looking back on the 1956 genetics conference in Qingdao, Li et al. (1996) praise the participants for fulfilling the CPC's promise of allowing one hundred schools of thought to flourish, writing, "science is international, a treasure belonging in common to all" (51). Conscious of how China was humiliated during the industrial revolution as well as the dangers of strictly following Soviet ideological constraints on science, the authors seek a new path that will support the development of science that does not serve as a means of exploitation.

"Introduction to Dialectics of Nature" became a compulsory course for STEM students. Guo $(2014,1838)$ does not speak favourably of the course, writing about his experience as student in 1996: 
While my teacher lectured, some students were absent, some students chatted, some students learned English, and some students did their homework for other courses. I estimate that the students who listened to my teacher in the classroom accounted for $50 \%$ of all students.

Guo's observations probably could be made of any required, non-major course in any country; we can also imagine many students sitting attentively in the front row.

Engels's thought inspired educators at a time when China's effort toward modernisation and the elimination of poverty began to show progress. Dialectics is still required of science and engineering students today, indicating that students who wish to advance their careers and interact well with the government can benefit from this subject, even if there may be some bored students in the back row of the classroom. As the country has focused on infrastructure development and improving their economic conditions in the Deng era (he is famous for saying "communism does not mean shared poverty"), the influence of Engels has been more on practical. As noted by Guo (2014, 1841 ) scholarship is likely to focus on "management, policies, and social problems".

One sociologist of science who visited China in 1980 wrote enviously of how the science of science, as he calls it, has the support of top leaders. In the U.S. and Europe, Weingart $(1981,14)$ writes, social studies of science "still struggles for institutional and professional support and recognition, Chinese scholars turning to that field do not have such worries" He goes on to write that in the U.S. and Europe, he and his colleagues "anxiously look to the natural sciences for approval [...] the science of science seems to have a bright future in China" (14-15). Due to the cold war and its aftermath, though, it is not easy to find this positive side.

\section{Dialectics in Capitalistic Science and Technology Studies}

Various manifestations of science and technology studies outside of China and Russia show similarities to the analyses inspired by Engels and implemented to support communist ideology. However, instead of finding common ground, some scholars have made a connection to political ideology, negatively assessing China's culture of science and engineering. One could turn this criticism around, saying that in capitalistic science, concern for human values is minimised due to the belief that science and technology are free from ideology and their impacts on the social fabric are beyond the purview of practitioners and institutions devoted to its practice.

The preface to the English translation by J. B. S. Haldane in 1939 pointed out the several positive aspects of Engels's analysis. Biologists after Haldane, including Stephen Jay Gould, Richard Dawkins, Richard Levins, and Richard Lewontin have praised Engels's insights (Royle 2014). Despite this commendation from a working scientist, Engels found little support among philosophers. György Lukács's footnote in his 1923 History and Class Consciousness is often cited to indicate the disdain the idea of dialectics existing in the natural science received (Foster 2013). In 1961, Jean Paul Sartre also bristled at the idea that human consciousness was a thing similar to the objects of nature (Remley 2012). These negative reactions seem to indicate that the way Engels's idea was received was to say that the dialectic between a human and an inanimate object was a flawed, dehumanising proposition. Lukács is willing to accept humans in a dialectic with history, but not with nature.

Increasingly, though, the use of Engels became identified with to interfere with scientific progress: shortly after Dialectics of Nature was translated into Russian, Merton (1938) was writing about a link between science and political ideals; to Merton, scientist must be "outraged" by any attempt to meet political aims (327). He goes on to advocate 
for the "purity of science," warning that science must not "become the handmaiden of theology or economy or state" (328). This mantle is taken up by others in the cold war. Mikulak (1958) suspects the "Communist party line" (49) and "philosophical restrictions upon Soviet astronomers" (50) have hindered science at the same time he writes that there are "no official statements" that CCCP approved or disapproved of any theories $(48)^{4}$. Similarly, Weiner (1985) writes of the way Dialectics of Nature became a dogma in the Soviet Union, and as a result, "the truth of natural science was subsidiary to the truth of Marxian 'science'" (689). Hu (2005) suggests that philosophy "was able to wantonly interfere" with science in China (186). Cao (2014) suggests that China cannot win Nobel Prizes because "China does not seem to believe [in] the existence of universally acknowledged values of science" and approaches science as "a pragmatic means to achieve the end of political leadership" (142). Engels's own warning, that science is operating in priestly worship of an unchanging universe, has done unheeded - indeed, it seems bolstered now as a passionate clergy in the face of evil.

The antipathy shown against Engels's dialectics is somewhat surprising given how much of the modern field of STS, like much critical theory, is based on a Marxist framework. After the notion of material history - the thinking that historical development is not inevitable and beyond the influence of humans direct - it is easier for a variety of critical theories that seek to show how what seem to be immutable characteristics of nature are really reification of ideologies. The dialectic between invention and society is clearly illustrated.

The STS concept of social constructivism in general seems indebted to Engels's Dialectic of Nature, even though few authors cite even Marxist ideas in general. Briefly speaking, the idea of social constructivism is that there are many simultaneous theories to explain phenomena or designs to solve technical challenges. This initial multiplicity is known as interpretative flexibility, meaning that the problem and its solutions have solutions that seem equivalent to the contemporary actors. Over a period of time, the relevant social groups find that some of the solutions fit in best with their ideals (thus reflecting economics, law, ideology, history, environment, and other factors of the social fabric). The common example of this is the formation of the so-called safety bicycle; who can go to a merchant and purchase an unsafe bicycle? This missing pole reflects the initial multiplicity of bicycle designs.

As STS proponents will tell us, there is no day in the nineteenth century to which we can return to find the supposed invention of the bicycle; instead, various actors proposed multiple designs that were simultaneous. After a time of stabilisation, the stunt bicycles that were favoured by the initial consumer group were supplanted by less risky models. As a marker of the culture at the time, gender differences were incorporated into the design, with a bicycle designed for women that had a low bar to accommodate their petticoats (Bijker 1995). The notion of co-creation can also be seen here. The low bar for women's bicycles was soon unnecessary because women began to wear more comfortable clothes. Nevertheless, the idea of a binary gender design had already been stabilized. This, when using this technology, a user must pick a gender, reinforcing norms of binary gender. In this example of co-creation, gender had an impact on design, and then the resulting design has a way of reifying the culture. The interplay of social and economic forces that gathered to create the modern bicycle design are also reminiscent of Engels, yet he is not cited by Bijker and most other main representatives of STS. Pickering $(1995,17$, footnote 26$)$ suggests without explanation

${ }^{4}$ Mikulak's paper was received by the journal in May 1957, a few months before the launch of Sputnik I showed that Soviet science was not as constrained by ideology as it might seem. 
in a footnote that the STS notion of co-creation of science and the social world is inspired by Engels. What seems like an obvious and necessary set of design choices what seems obviously to be a bicycle - is in fact the result of a conflicting set of assumptions that evolved over time seems nothing but a dialectical analysis.

Allied with social construction, the proponents of actor-network theory seem to ratify the idea that a complex interchange of ideology and history results in products that are always social. Latour and Woolgar (1986, 24), for instance, cite Marx's ideas of use value and of praxis in their foundational text Laboratory Life, but Engels and any mention of dialectics is unfortunately missing. They do, however, take on Merton, pointing out that he unjustly separates the scientific and the social worlds in what seems like a reaffirmation of Engels. Latour and Woolgar, embedded in Salk's vaccine laboratory, try to make an insider's view of science - doing an ethnographic study of what scientists do, as opposed to what they say they do. While scientists might claim that their inquiry is objective and free from social concerns, Latour and Woolgar point out that the devices they use are themselves cultural because they reflect the history of a discipline, not to mention the more obvious connection that the fact of setting an agenda and finding funding influences what will be investigated and how. In 1987, a group of scholars gathered at a workshop at the University of Twente in the Netherlands to explore the social analysis of technology that resulted in the first of several famous STS anthologies, Shaping Technology/Building Society. Bijker and Law (1992) in their introduction mention that technology is developed in conflict. Apart from the common assumption that technology is developed on its own, isolated from social concerns, the authors in this volume show how various solutions compete for audiences until one is established as the standard. After the initial conflict, the solution seems inevitable and unchangeable, almost a fact of nature.

In scientific fields, the impact of ideology that Engels predicted has been demonstrated many times, even if the authors seem not to know they are indebted to him. Galison (1985) uses the story of the bubble chamber in high-energy physics to show how the choice of a technology intersects the organisation and the substance of inquiry. As large-scale particle accelerators were made, however, the various options for conducting science collapsed onto bubble chambers. The paradigm in place for postWorld War II physics was the interdisciplinary, team-based approach of big science; even though researchers during the first phase could work individually or in teams, after the bubble chamber, it was only possible to do particle physics research in teams that numbered in the thousands. Schiebinger (1993) looks into the science behind the decision to exclude women from voting in the democratic revolutions in France and the United States. Surprisingly, she points to Linnaeus's decision to call humanity's portion of the animal kingdom mammals due to his belief that women should remain home to manage the private sphere while men went into the town to take care of business in the public sphere. Only with mammals, Schiebinger points out, was a sex-determinant characteristic found in only half of the population used as a name. Hacking (1999) takes on what would seem to be the least possibility for social construction - a rock only to show how tensions between authority, commercial use, and gender result in what seems to be the natural and obvious definition of dolomite. In a popular context, it would seem as if scientists are using an objective methodology to understand a stable and unchanging universe. Without critiquing capitalism directly, they point out that accepted technological designs and scientific findings are not inevitable and question the ideology of universal science.

Some STS thinkers who are more broadly known beyond STS circles do not cite Engels or Marx, even though they sound indebted to his thinking. Kuhn (1962) seems 
particularly indebted to the idea of dialectic even though he does not directly cite any of Marx's ideas. His famous notion of paradigm shift relies on some of the same observations noted by Engels in the history of astronomy. The idea that contradictions between normal science and new data likewise seem like a dialectical method. Pacey (1990) develops a concept he calls "technological dialogue" to describe the reason why technology does not easily transfer from one social circumstance to another. To understand the fact that both Asia and Europe had moveable type - and the reason why the earlier invention in China and Korea had a different impact than the much later invention in Germany - Pacey tells his readers to think about technology as a way of getting work done that carries ideology along with it instead of an inert device. As proof, he shows how at each stage of a device's diffusion, a "dialogue" takes place between the original circumstances and the new social context. This negotiation to resolve conflicts also seems indebted to a dialectical form of thinking.

These texts do not directly cite Dialectics of Nature and, although STS scholars often point out the internal contradictions of capitalistic science, they do not overtly make a critique of capitalism. It seems plausible that the use of Engels in the Soviet Union and the People's Republic of China and the tenuous position of science studies in universities has led these scholars to tread lightly during the Cold War. The connections, however, seem obvious. Despite the lack of Engels-citations, STS scholars certainly share with Engels the criticism of a single, unchanging reality and the notion of Enlightenment objectivity.

This self-censorship is less alarming that texts that directly address Marxist themes without understanding Engels's theory. Winner $(1977,82)$ makes the perplexing proposition that Dialectics of Nature promotes the idea that "individuals, classes, and societies have little autonomy to guide their own character or development" (82). MacKenzie and Wajcman $(1985,69)$ mention Engels obliquely in their commentary, crediting him unfairly for a non-dialectical notion that technology inevitably causes social change (69). Noble $(1997,87)$ seems to be inspired by Engels's observation that science failed to replace religious conceptions of nature, but he in fact criticises Marx for turning the quest for the means of production into a mechanism of spiritual "deliverance". Later, Noble (2011) gestures to Marx in the title and quotes him in epigraphs but makes little mention of communism and mentions neither Engels nor dialectics. Taking the lead from Merton (1938) and Mikulak (1958), these scholars either blame Engels for determinism or leave out obvious connections to their work, suggesting he is irrelevant ${ }^{5}$.

Engels's sense of managing the unintended consequences of technology choice has also been inspirational, even if he is not cited. In the foundational text of the appropriate technology movement, Schumacher (1973) discusses alienation, citing Marx, even if he suggests that Marx was wrong. Nevertheless, the interplay between technical development and its social consequences seems similar to Engels's analysis of technology. STS literature on feminist design involves experts getting into the minds of users and users participating in the design process as a means of distributing equity (Feldman 1999). Similarly, STS in the field of international development suggests how breaking down the inequality between the experts installing clean water systems and the citizens of developing countries can have a positive effect. Although an engineer might be focused on cost-effective systems that minimize the time to install and solve

${ }^{5}$ Bimber (1990) has carefully analysed three prominent forms of technological determinism in order to show that Marx does not fit into this category; he writes, "the intentional use of technology by human actors is an important theme in Marx's work, one quite contradictory in nature to technological determinism", continuing to say that whatever natural or inherent effects technology tends to produce are overcome by wilful human actions" (348). 
technical challenges elegantly, what experts think is a good project that will help people can have devastating effects on autonomy miss an opportunity to enhance local governance (Clemens et al. 2002). Like Engels, Schumacher and others also point out that technological development does not obligatorily demolish local culture, especially when one is willing to abandon the vaunted place of the expert and accommodate a variety of solutions.

Another way of implementing this idea is to consider how emphasising science without attending to social effects may not solve pressing contemporary issues. Tiles (1997), for one, notes that science is essential in reducing world hunger. However, philosophy has a role in directing the research, and Tiles cites Dialectics of Nature to show how the Chinese emphasis on interconnectedness is necessary. She writes:

There is nothing particularly scientific or particularly rational in the way of proceeding to try to solve all practical problems by developing a product in a research laboratory, through the application of theoretical science, presuming that it can be put out into the world for universal application. This makes sense only for those who can presume unlimited resources (to pay the costs of suitably modifying the environment so that it at least approximates the conditions of the laboratory in which the development work was carried out) and in areas where it can be presumed that the simplifications in the problem specification necessarily entailed by such a strategy have not omitted factors crucial to the success of implementation of the 'solution' in real world situation (Tiles 1997, S173).

Because the reward systems and goals of institutional science are not organized to benefit the poor, science is unlikely to solve problems like world hunger, Tiles writes.

\section{Implications for Future Work}

As this paper has shown, it is clear that Engels was not, in fact, trying to remove human agency or create an alternative form of science. Instead, we can see how his critique of idealism in science is still relevant to critical thinking about STEM today. The problems he witnesses in the exploitative science at the behest of capitalism during the age of colonialism resonate only more strongly in our technological age. Making this connection has two important implications. For one, it opens a channel for collaboration between STS scholars inside and outside China, particularly those who are interested in strategies for sustainable development.

First of all, understanding Engels's dialectic method can help build bridges between STS researchers within and outside of China. China's success in alleviating poverty particularly under Deng's rubric of socialism with Chinese characteristics in the years since 1978 - has been guided by Engels's insights. Unfortunately, the ability of science and technology policy to produce sustainable and equitable development seems like a fringe theory outside of China. It is in this domain that Engels's critique can be used today. As a counter to histories of the Internet that suggest the kernel of an idea in the heart of the military-industrial complex spread out to become a technology that welcomed all humans, a dialectical method can show the competing forces, both within the U.S. and without, that forged the Internet. Similarly, dialectical thinking can help problematise simplistic thinking about the opportunities that supposedly come from unleashing the unidirectional power of technology worldwide.

Secondly, Dialectics of Nature points toward an opportunity to revisit current trends in engineering education. One key notion is adding the liberal arts to provide an interdisciplinary science and engineering education, a practice known as STEAM. Taking 
the acronym developed by the U.S. National Science Foundation for science, technology, engineering, and management (STEM), Yakman (2008) suggested that educators should incorporate the arts, adding A to STEM to get STEAM. There is a practical side to this proposal; it is in the arts and crafts classroom where students can build things. Several proposals have been made to take the materials and skills used in a middle school classroom to provide scientific investigation (Gilbert and Borgerding 2019). Although Yakman was quite open in her intention to include ideas about history and sociology in her paradigm for STEAM, even a cursory review of the literature shows how this project has been derailed by well-meaning educators who have transformed STEAM with ideologies of the "maker" movement to teach students job skills. Allington et al. (2016), for instance, have criticised the maker movement in the humanities when its proponents "disavow scholarly endeavor that is overtly critical of existing social relations". The intellectual tradition established by Engels can serve as a useful counter to the effort to end critical thinking in the humanities with neo-liberal goals of making education relevant to the job market.

The polarization of the Cold War still has its effects today in STS because of the mistaken notion that Marxism seeks to remove human agency from the process of history. This misreading is easily seen by studying Engels's thoughts on applying dialectics to science. Although he clearly resents the division of labour in science and the ways in which bourgeois notions limited scientific progress, he does not see science as inevitably a bourgeois pursuit. He writes:

The men who founded the modern rule of the bourgeoisie had anything but bourgeois limitations. On the contrary, the adventurous character of the time inspired them to a greater or lesser degree. There was hardly any man of importance then living who had not travelled extensively, who did not speak four or five languages, who did not shine in a number of fields. ... The heroes of that time were not yet in thrall to the division of labour, the restricting effects of which, with its production of one-sidedness, we so often notice in their successors. But what is especially characteristic of them is that they almost all live and pursue their activities in the midst of the contemporary movements, in the practical struggle; they take sides and join in the fight, one by speaking and writing, another with the sword, many with both (Engels 1925, 319-320).

Thanks are due in part to the Soviet and Chinese intellectuals who saw in Engels an opportunity to counter what seemed like an inevitable march of technical development with the sense that human beings could monitor and redirect the forces shaping society. Additionally, the efforts of reform-minded intellectuals outside of communist countries show a way of understanding that the impact of science and technology is not inevitable.

\section{References}

Allington, Daniel, Sarah Brouillette, and David Golumbia. 2016. Neoliberal Tools (and Archives): A Political History of Digital Humanities. Los Angeles Review of Books, 1 May 2016. https://lareviewofbooks.org/article/neoliberal-tools-archives-political-history-digitalhumanities/

Bijker, Wiebe E. 1995. Of Bicycles, Bakelites, and Bulbs: Toward a Theory of Sociotechnical Change. Cambridge, MA: The MIT Press.

Bijker, Wiebe E. and John Law, eds. 1992. Shaping Technology/Building Society: Studies in Sociotechnical Change. Cambridge, MA: The MIT Press. 
Bimber, Bruce. 1990. Karl Marx and the Three Faces of Technological Determinism. Social Studies of Science 20 (2): 333-351.

Cao, Cong. 2014. The Universal Values of Science and China's Nobel Prize Pursuit. Minerva $52(2): 141-160$.

Chamberlain, Muriel E. 2013. The Scramble for Africa [3rd Edition]. London: Routledge.

Cheng, Yinghong. 2013. Ideology and Cosmology: Maoist Discussion on Physics and the Cultural Revolution. In Mr Science and Chairman Mao's Cultural Revolution: Science and Technology in Modern China, edited by Chunjuan Nancy Wei and Darryl E. Brock, 197231. New York: Lexington Books.

Clemens, Bruce, Andrew W. Karp, and Maria Papadakis. 2002. The People's Water: Technology Transfer and Community Empowerment in Guatemala. In Research in Science and Technology Studies, Vol. 13, edited by Marianne de Laet, 105-127. New York: JAI.

de Sousa Santos, Boaventura. 2018. The End of the Cognitive Empire: The Coming of Age of Epistemologies of the South. Durham, NC: Duke University Press.

Desmond, Adrian and James Moore. 2011. Darwin's Sacred Cause: How a Hatred of Slavery Shaped Darwin's Views on Human Evolution. Chicago: University of Chicago Press.

Elzinga, Aant. 1981. The Science of Science in China: Report by a Specialist in Science Policy. Science, Technology, \& Human Values 6 (35), 18-21.

Emery, A. 1935. Dialectics versus Mechanics. A Communist Debate on Scientific Method. Philosophy of Science 2 (1): 9-38.

Engels, Friedrich. 1925. Dialectics of Nature. In Marx \& Engels Collected Works (MECW) Volume 25, 311-588. London: Lawrence \& Wishart.

Fan, Dainian and Robert S. Cohen, eds. 1996. Chinese Studies in The History and Philosophy of Science and Technology. Dordrecht: Springer.

Feldman, Roberta M. 1999. Participatory Design at the Grass Roots. In Design and Feminism: Re-visioning Spaces, Places, and Everyday Things, edited by Joan Rothschild, 135148. New Brunswick: Rutgers.

Foster, John Bellamy. 2013. Marx and the Rift in the Universal Metabolism of Nature. Monthly Review 65 (7). Accessed 13 November, 2020. https://monthlyreview.org/2013/12/01/marx-rift-universal-metabolism-nature/

Galison, Peter. 1985. Bubble Chambers and the Experimental Workplace. In Observation, Experiment and Hypothesis in Modern Physical Science, edited by Peter Achinstein and Owen Hannaway, 309-372. Cambridge, MA: The MIT Press.

Gao Lu. 2016. From Dialectics of Nature to STS: The Historical Evolution of Science Studies in China. In Science Studies During the Cold War and Beyond, edited by Elena Aronova and Simone Turchetti, 267-288. New York: Palgrave.

Gilbert, Andrew and Lisa Borgerding. 2019. Possibilities and Potential with Young Learners: Making a Case for STEAM Education. In STEM Education: An Emerging Field of Inquiry, edited by Tasos Barkatsas, Nicky Carr and Grant Cooper, 101-116. Boston: Brill Sense.

Guo, Yuanlin. 2014. The Philosophy of Science and Technology in China: Political and Ideological Influences. Science and Education 23 (9): 1835-1844.

Hacking, lan. 1999. The Social Construction of What? Cambridge, MA: Harvard University Press.

Hou, Jixia 侯吉侠. 1985. Engineering College Students Welcome Dialectics of Nature 工科大 学生欢迎自然辩证法. Research on Dialectics of Nature 1: 62-64.

Hu, Danian. 2005. China and Albert Einstein: The Reception of the Physicist and his Theory in China 1917-1979. Cambridge, MA: Harvard University Press.

Jiang, Zhenhuan 姜振寰. 1985. Survey of Research on History of Technology Abroad 国外技 术史研究概况. Research on Dialectics of Nature 2: 70-74.

Joravsky, David. 1955. Soviet Views on the History of Science. Isis 46 (1), 3-13.

Kuhn, Thomas S. 1962. The Structure of Scientific Revolutions. Chicago, IL: University of Chicago Press. 
Latour, Bruno and Steven Woolgar. 1986. Laboratory Life. Princeton, NJ: Princeton University Press.

Li, Peishan, Meng Qinzhe, Huang Qinghe and Huang Shu'e. 1996. The Qingdao Conference of 1956 on Genetics: The Historical Background and Fundamental Experiences. In Chinese Studies in The History and Philosophy of Science and Technology, edited by Dainan Fan and Robert S. Cohen, 41-54. Dordrecht: Springer.

MacKenzie, Donald and Judy Wajcman, eds. 1985. The Social Shaping of Technology: How the Refrigerator Got Its Hum. Philadelphia: Open University Press.

Merton, Robert K. 1938. Science and the Social Order. Philosophy of Science 5 (3): 321-337.

Mikulak, Maxim W. 1958. Soviet Philosophic-Cosmological Thought. Philosophy of Science 25 (1): 35-50.

Noble, David F. 2011. Forces of Production: A Social History of Industrial Automation. New Brunswick, NJ: Transaction.

Pacey, Arnold. 1990. Technology in World Civilization. Cambridge, MA: The MIT Press.

Pickering, Andrew. 1995. The Mangle of Practice: Time, Agency and Science. Chicago: University of Chicago Press.

Remley, William L. 2012. Sartre and Engels: The Critique of Dialectical Reason and the Confrontation on the Dialectics of Nature. Sartre Studies International 18 (2): 19-48.

Royle, Camilla. 2014. Dialectics, Nature and the Dialectics of Nature. International Socialism 141: $97-118$.

Schiebinger, Londa. 1993. Nature's Body: Gender in the Making of Modern Science. Boston, MA: Beacon.

Schumacher, Ernst F. 1973. Small is Beautiful: A Study of Economics as if People Mattered. London: Blond and Briggs.

Shapin, Steven and Simon Schaffer. 2011. Leviathan and the Air-Pump: Hobbes, Boyle, and the Experimental Life. Princeton: Princeton University Press.

Tiles, Mary. 1997. Science and the Politics of Hunger. Philosophy of Science 64, Supplement. Proceedings of the 1996 Biennial Meetings of the Philosophy of Science Association. Part II: Symposia Papers, S161-S174.

Wang, Zuoyue. 2002. Saving China Through Science: The Science Society of China, Scientific Nationalism, and Civil Society in Republican China. Osiris 17, 291-322.

Weiner, Douglas R. 1984. Community Ecology in Stalin's Russia: "Socialist" and "Bourgeois" Science. Isis 75 (4), 684-696.

Weingart, Peter. 1981. The Science of Science in China: Report by a Sociologist of Science. Science, Technology, \& Human Values 6 (2): 14-17.

Whewell, William. 1840. The Philosophy of the Inductive Sciences, Founded upon their History, Volume 1. London: John W. Parker.

Winner, Langdon. 1977. Autonomous Technology: Technics-out-of-Control as a Theme in Political Thought. Cambridge, MA: MIT Press.

Xu, Liangying. 1996. Essay on the Role of Science and Democracy in Society. In Chinese Studies in The History and Philosophy of Science and Technology, edited by Dainian Fan and Robert S. Cohen, 5-11. Dordrecht: Springer.

Yakman, Georgette. 2008. ST $\sum @ M$ Education: An Overview of Creating a Model of Integrative Education. In Proceedings of the Pupils' Attitudes Towards Technology (PATT-19) Conference: Research on Technology, Innovation, Design \& Engineering Teaching, 335358. Salt Lake City: ITEEA.

Yang, Di 杨迪 and Zeng Guoping 曾国屏. 1985. Exploration of American Science and Technology Strategy in the 1980s 八十年代美国科技战略的探索. Research on Dialectics of Nature 2: 75-76.

Yu, Guangyuan. 1996. On the Emancipation of the Mind. In Chinese Studies in The History and Philosophy of Science and Technology, edited by Dainan Fan and Robert S. Cohen, 1-3. Dordrecht: Springer. 


\begin{abstract}
About the Author
Christopher Leslie

Christopher Leslie is the chair of the International Federation of Information Processing's working group on the History of Computing (http://ifipwg97.org) and Creative Consultant for Zhejiang Hexin Group in Yunhe, China. A two-time winner of a Fulbright fellowship, he has taught at Hunter College, John Jay College, New York University, Polytechnic University, Universität Potsdam, and the South China University of Technology. Dr Leslie was born and raised in western New York State. He took his M.A. and Ph.D. from the City University of New York Graduate Center in New York City. His research interests include the interactions among science, technology, and culture.
\end{abstract}

